\title{
Frank Popper, Roy Ascott e Jeffrey Shaw: visões de um futuro tecnológico e participante nas décadas de 1960 e $1970^{1}$
}

\author{
MARCO PASQUALINI DE ANDRADE
}

Marco Pasqualini de Andrade possui graduação em Arquitetura pela Universidade de São Paulo (1989), mestrado em Arquitetura e Urbanismo pela Universidade de São Paulo (1999) e doutorado em Artes pela Universidade de São Paulo (2007). Realizou estágio de pósdoutoramento na Universidade Federal do rio de Janeiro (2018). Membro do Comitê Brasileiro de História da Arte (CBHA) e associado a Latin American Studies Association (LASA) e Association of Art Historians (AAH). Atualmente é professor adjunto da Universidade Federal de Uberlândia. Tem experiência na área de Artes Visuais, com ênfase em História e Crítica da Arte, atuando principalmente nos seguintes temas: arte contemporânea brasileira (décadas de 1960 e 1970), arte contemporânea internacional, arte na região do Triângulo Mineiro e entorno, crítica de arte, apresentação e curadoria de exposições de arte, história da arquitetura moderna e contemporânea.

AFILIAÇÃO: Universidade Federal de Uberlândia (UFU) Uberlândia MG Brasil

\footnotetext{
$\overline{1}$ Este artigo constitui uma versão do texto apresentado no IX Congreso Internacional de Teoría e Historia de las Artes / XVII Jornadas del CAIA, em Buenos Aires, Argentina, em setembro de 2017. 


\begin{abstract}
RESUMO
O artigo trata um viés tecnológico e participativo desenvolvido nas décadas de 1960 e 1970 e que ainda não se encontra devidamente explorado pela História da Arte na contemporaneidade. Tal vertente, derivada das tendências de arte op e arte cinética, encontra seu desdobramento em uma abordagem na qual a pesquisa tecnológica e de novos materiais alia-se a um processo de obra aberta, como descrito por Umberto Eco, que se dirige a uma efetiva participação do espectador. Embora a arte comportamental tenha encontrado interesse dos investigadores, o mesmo não se aplica a uma parcela de teóricos e artistas, talvez devido a seu vínculo com a ainda desprezada e subvalorizada arte op, considerada fria e mecânica. É, pois, objetivo desse artigo contribuir para o resgate de tal produção teórica e artística, tomando como base a teoria elaborada por Frank Popper, especialmente em Art - action and participation, de 1975, e como estudo de caso os textos e proposições do artista britânico Roy Ascott e do australiano Jeffrey Shaw.
\end{abstract}

\title{
PALAVRAS-CHAVE
}

Arte op, arte cinética, Frank Popper, Roy Ascott, Jeffrey Shaw.

\section{ABSTRACT}

The article deals with a technological and participatory art developed in the 1960s and 1970 s and not yet adequately explored by contemporary art history. This aspect, derived from the tendencies of op art and kinetic art, finds its unfolding in an approach in which technological research and new materials are allied to a process of open work, as described by Umberto Eco, which is directed to an effective participation of the spectator. Although behavioral art has found researchers' interest, the same does not apply to a portion of theorists and artists, perhaps because of its link to the still despised and undervalued op art, considered cold and mechanical. It is therefore the objective of this article to contribute to the rescue of such theoretical and artistic production, based on the theory elaborated by Frank Popper, especially in Art

- action and participation, 1975, and as a case study the texts and propositions of the British artist Roy Ascott and the Australian artist Jeffrey Shaw.

\section{KEYWORDS}

Op art, kinetic art, Frank Popper, Roy Ascott, Jeffrey Shaw. 


\section{Introdução: Arte Cinética e Arte Op}

As tendências perceptivas e tecnológicas são, em certa medida, desdobramentos das vertentes construtivas do início do século $X X$, baseadas na abstração e em construções visuais formais.

As duas principais exposições: Le Mouvement, na Galeria Denise René, em Paris, em 1955 e The Responsive Eye, organizado por William Seitz, no MOMA em 1965, estabelecem alguns parâmetros de entendimento que se conformam como paradigmas, especialmente em relação à importância da tecnologia e da participação do espectador.

Victor Vasarely (1955), escreve por ocasião da exposição francesa, sobre a relação de tais tendências com a exploração de novas descobertas científicas e tecnológicas, defendendo a ruptura ou síntese entre as categorias tradicionais da arte, e propondo a conquista ambiental:

Paralelamente ao declínio da técnica ancestral da pintura, continua a experimentação de materiais novos (aplicações químicas) e a adoção de novas ferramentas (descobertas da física). Hoje, rumamos ao abandono total da rotina em direção a integração da escultura e a conquista das dimensões superiores ao plano. (VASARELY, 1955) (tradução nossa). ${ }^{2}$

Por outro lado, indica que isso será feito através de uma possível conjunção com o cinema e a tridimensionalidade. E ainda, enaltece a importância da percepção do espectador, e preconizando sua efetiva participação, principalmente lúdica, na obra. Todos esses elementos serão de fato significativos na continuidade de tais experiências, pelas décadas seguintes.

Em 1956, o artista George Rickey usou o termo "kinetic sculpture" como título de um artigo no qual explanava o desenvolvimento de seus móbiles e estruturas móveis. Defende o conhecimento técnico e científico como base para a criação artística, de certo modo estabelecendo um rigor racional a ser adicionado à intuição pela abstração em movimento, a exemplo de Calder.

Estava tentando estabelecer um tipo expressivo de ordem, que toda arte possui, e desafiar o olho e a mente com um dispositivo mecânico que empregasse, ainda que parecesse desafiar, a gravidade. Suas partes moveis seriam organizadas por motivos mecânicos tanto quanto visuais - em suma, uma maquina. (RICKEY, 1956, p.156) (tradução nossa). ${ }^{3}$

\footnotetext{
$\overline{2}$ Parallelements au declin de la technique ancestrale de la peinture, se poursuit l'experimentation de materiaux neufs (aplications chimiques) et l'adoption de nouveaux outils (decouvertes de la physique)... A presente, nous allons vers l'abandon total de la routine, vers l'integration de la sculpture et la conquete des DIMENSIONS SUPERIEURES au plan (VASARELY, 1955).

3 I was attempting to establish an expressive kind of order, which all art has, and to challenge the eye and the mind with a mechanical device which employed, yet appeared to defy, gravity. Its moving parts were arranged for mechanical as well as visual reasons - in short a machine (RICKEY, 1956, p. 156).
} 
O termo "Op art" aparece em 1964, primeiramente na resenha de Donald Judd para a edição de outubro da Arts Magazine sobre a exposição de "Julian Stanczak - optical paintings" (JUDD, 1964, p.69). Posteriormente, o termo também foi citado na revista Time, no artigo de Jon Borgzinner "Op art - pictures that attack the eye", enfatizando a recepção visual do espectador (BORGZINNER, 1964).

A mostra The Responsive Eye acabou se tornando a mais importante referência, mesmo aglutinando artistas muito diferentes entre si e forçando um determinado entendimento através da organização do texto e da montagem.

Ann Reynolds (2003) aborda de modo interessante como Seitz enxerga a expansão da op art para além do mundo da arte, apagando as fronteiras dentro e fora da galeria, e abrindo a experiencia perceptual para padrões abstratos do ambiente urbano e natural.

De fato, o sucesso de público e sua ostensiva utilização em publicidade, cartazes, moda e objetos decorativos contrastou com uma fria e irônica recepção crítica, que a entendia como um simples jogo óptico ou um fascínio ingênuo sobre a ciência e a tecnologia.

Thomas B. Hess (1965) lançou diversos comentários ácidos sobre a exposição, desde sua capacidade doentia de causar vertigem e dor de cabeça, seu uso alucinógeno, até a afirmação de que a participação do espectador seria passiva (como zumbis) e que utilizaria uma pseudo-ciência e uma tecnologia comercial fácil.

Do mesmo modo, Barbara Rose também disparou contra a Op art, questionando seu significado artístico vazio e sem espírito e a relação arte-ciência, que considera falsa:

[...] A arte puramente "óptica", baseada em livros didáticos e experimentos de laboratório, teoria, equação e provas, é vazia e sem espírito, embora possa sacudir os nervos e atacar os globos oculares. [...] Outra ideia igualmente falsa que uma mostra dessa natureza coloca é a que a ciência e a arte têm algo a ver uma com a outra (ROSE, 1965, p. 30) (tradução nossa) ${ }^{4}$

Esse desdém pelo movimento é perceptível também na História da Arte. Se verificarmos nos principais manuais sobre arte moderna e contemporânea qual espaço relativo a tendência ocupa nos livros, veremos que não há preocupação em problematizar ou trazer significados, mas apenas de registrar sua existência histórica.

Esse "preconceito" existe mesmo após os desdobramentos em direção a propostas ambientais. Podemos perceber que uma vertente mais sociológica, comportamental e conceitual domina a reflexão sobre a arte, enquanto a vertente mais tecnológica e sensorial é relegada a uma segunda categoria, de certo modo inferiorizada.

Um novo interesse pela Op art surge apenas muitas décadas depois principalmente a partir do ano 2000, quando são organizadas exposições retrospectivas mais abrangentes.

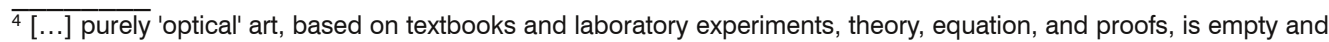
spiritless, though it may jangle the nerves and assault the eyeballs. [...] Another idea a show of this nature puts across is the equally false one that science and art have something to do with one-another (ROSE, 1965, p. 30).
} 
Podem-se citar Force Fields: Phases of the Kinetic, no Museu de Arte Contemporanea de Barcelona e na Hayward Gallery, em Londres, organizada por Guy Brett (que incorpora os artistas latino americanos); em 2005, L'CEil moteur. Art optique et cinétique, organizada pelo Musee de l'art Moderne et Contemporain de Strassbourg; e duas exposições em 2007: Op Art, na Schirn Kunsthall em Frankfurt, com curadoria de Martina Weinhart; e ainda no mesmo ano Optic Nerve: Perceptual Art of the 1960s, realizada no Columbus Museum of Art.

Todas essas mostras mencionavam, de certo modo, a incompreensão anterior pelo movimento e seu aspecto inovador ou revolucionário, de modo a tentar reinserir a Op art de maneira apropriada na História da Arte.

\section{A teoria de Frank Popper}

O teórico tcheco, naturalizado francês, Frank Popper, na contramão da crítica dominante, foi responsável, ainda na década de 1960, por fazer um mapeamento dos artistas op e cinéticos. Sua tese de doutorado em Paris, e a publicação do livro Naissance de l'art cinétique, em 1966, já mostram claramente a direção de seu pensamento. Torna-se de fato engajado na divulgação dessas tendências, organizando exposições e discutindo o assunto em suas aulas na Université de Paris e em Vincennes.

Em 1975 publica Arte, acao e participação, obra na qual avança, em direção às proposições ambientais participativas.

Popper parte da noção de "ambiente", considerado como ponto de encontro privilegiado entre os fatos físicos e psicológicos que animam o universo. Diferente do senso arquitetural, a prática artística buscaria a dinâmica e a consciência do espaço, sob a forma de proposição simbólica ou metafísica, demandando uma resposta intelectual, mas também física por parte do espectador, como uma experiência plurisensorial (POPPER, 1980).

O artista seria um moderador de uma confrontação dramática do espectador a uma situação perceptiva, não limitada em intensidade nem duração.

A criatividade do mundo contemporâneo demandaria uma união de arte e ciência, com destaque para o papel da tecnologia e dos novos materiais.

De uma participação lúdica, o espectador ampliaria sua capacidade criativa através de uma experiência total, um espaço sociológico autêntico e global.

Chama a atenção de Popper o significado cultural prospectivo das obras realizadas através do conhecimento científico e de elementos tecnológicos contemporâneos empregados de modo efetivo ou simbólico pelos artistas. De tal modo que a noção de futuro estaria imbricada nessa concepção, ou seja, a experimentação da tecnologia pela arte seria um modo de buscar novas maneiras de habitar o mundo, de conhece-lo, e de desenvolver o potencial criativo da humanidade, através de uma aproximação efetiva e participativa do espectador, que mais que perceber pelos sentidos, experimenta e conhece com seu próprio corpo.

\section{Estudo de caso 1: Roy Ascott}

Roy Ascott é considerado por Popper um dos primeiros artistas a criar um 
apelo à participação total do espectador, especialmente por sua teoria e prática junto à telemática.

Ascott nasceu em 1934 em Bath, Inglaterra. Estudou em Newcastle com Richard Hamilton e Victor Pasmore. Dedicou-se a atividades pedagógicas, implantando o Groundcourse, um modelo experimental de ensino.

Em um texto de 1964, Ascott (2002) propõe que a principal qualidade da arte moderna em relação à arte tradicional seria seu papel "comportamental", que tenderia a criar um futuro configurado por uma mudança radical criativa baseada na visão cibernética. $\mathrm{O}$ espectador guiaria a ação a partir de seu feedback e de sua decisão. A obra de arte estaria em um constante estado de transição, o espectador sendo responsável pela finalização, mas mantendo uma permanente condição de jogo.

O processo ou espírito cibernético geraria um constante fluxo de relações novas para ativar o diálogo artista - obra - espectador. Daí a importância dos novos materiais sintéticos e do computador pensado como ferramenta tecnológica para abrir caminhos e potência à invenção artística.

Em 1968, Ascott apresenta sua noção de um futuro imprevisível como essência da atividade artística:

O paradoxo que enfrentamos como artistas falando sobre nosso trabalho é que o futuro é tudo que nos interessa, e essa é precisamente a parte de nossa atividade que deve permanecer necessariamente imprevisível (ASCOTT, 1968, p. 105) (tradução nossa). ${ }^{5}$

A seguir, soma o termo futuribles (futuríveis) a sua proposta behaviorista de arte:

Em vez de figuração - prefiguração: a definição de futuriveis. Pictomancia - adivinhação de possíveis futuros pela analise estrutural. Estamos conscientes em gerar futuríveis - talvez porque por mais que sonhemos com futuros alternativos mais mutável o presente se verifica. E a mudança é o que queremos - por si mesma. Esta é a essência da arte comportamental - gerar mudança é o objetivo do artista comportamental (ASCOTT, 1996) (tradução nossa). ${ }^{6}$

A obra artística de Ascott se desenvolve dentro de experiências que envolvem justamente os dois pontos: uma noção de incompletude e a necessidade de que o espectador "entre no jogo", participando, para dar continuidade ao processo iniciado pelo artista. Seja em um objeto ainda "visual", como suas Changing Paintings, seja pela criação de situações comportamentais interativas.

\footnotetext{
$\overline{5}$ The paradox we face as artists writing about our work is that the future is all that interest us, and that is precisely the part of our activity which must remain necessarily unpredictable (ASCOTT, 1968, p. 105).

${ }^{6}$ Instead of figuration - prefiguration: the delineation of futuribles. Pictomancy - the palmistry of paintings divination of possible futures by structural analysis. [...] We are very much concerned with generating futuribles maybe that's because the more we can dream up alternative futures the more changeable the present can become. And change is what we are all about - change for its own sake. That is the essence of behaviourist art, and generating change is the aim of the behaviourist artist. (ASCOTT, 1996).
} 


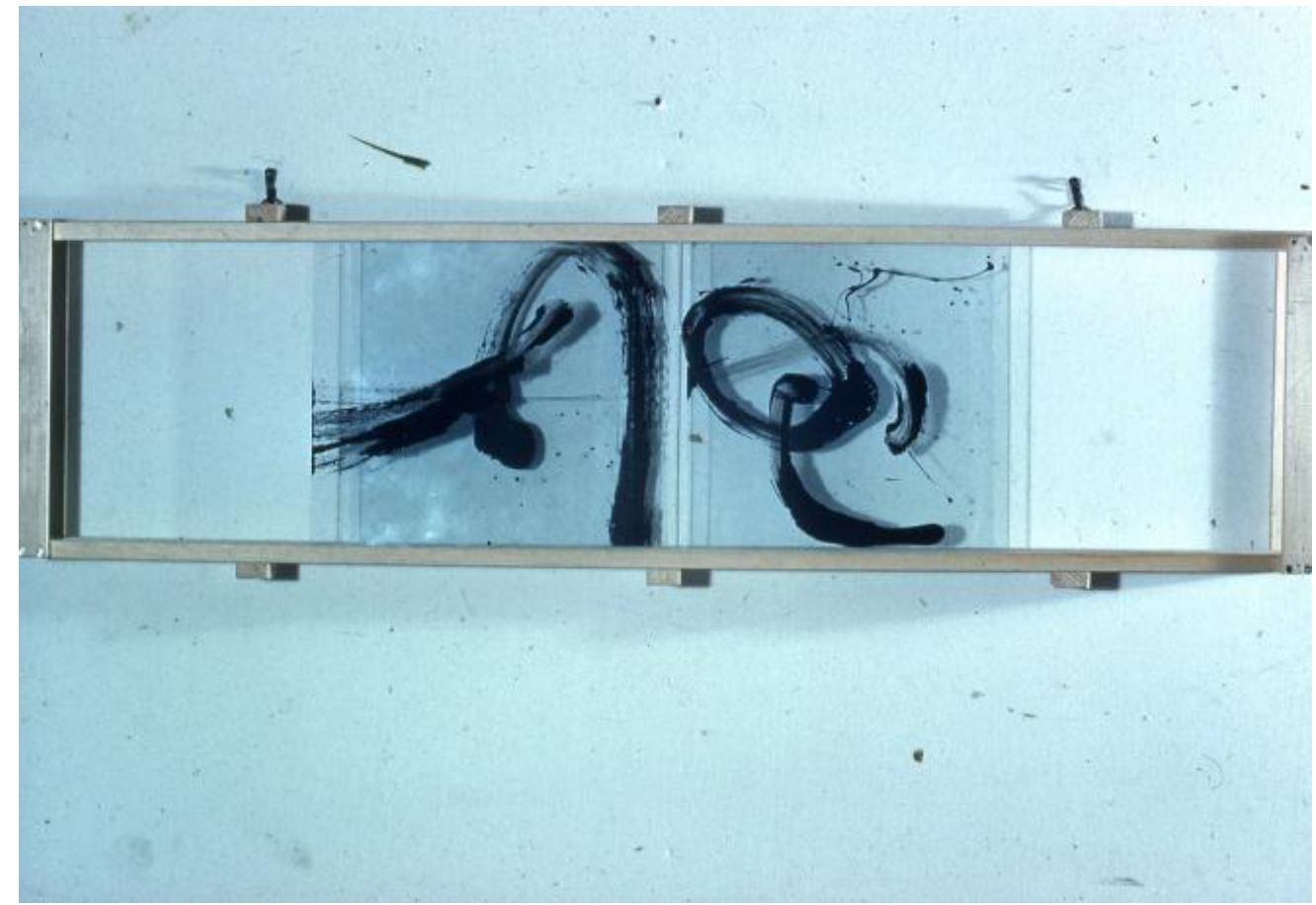

ASCOTT, Changing paintings, 1960.

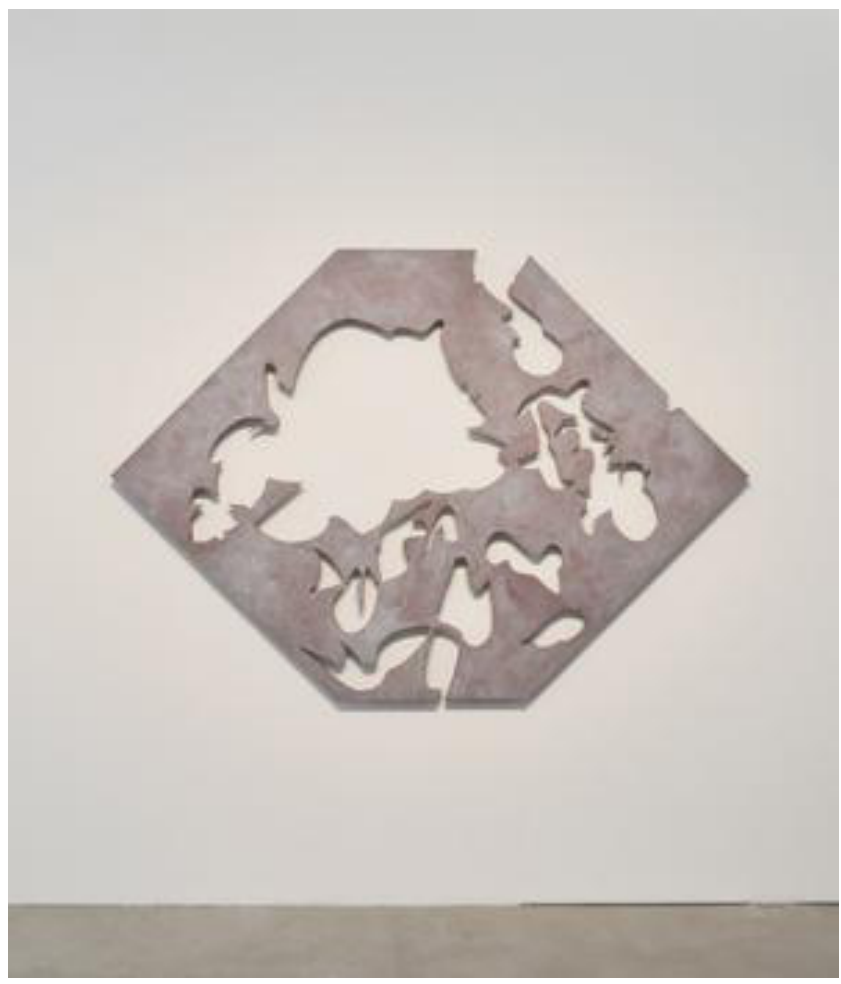

ASCOTT, Cloud Template, 1966.

ouvirouver Uberlândia v. 14 n. 2 p. 310-321 jul.|dez. 2018 


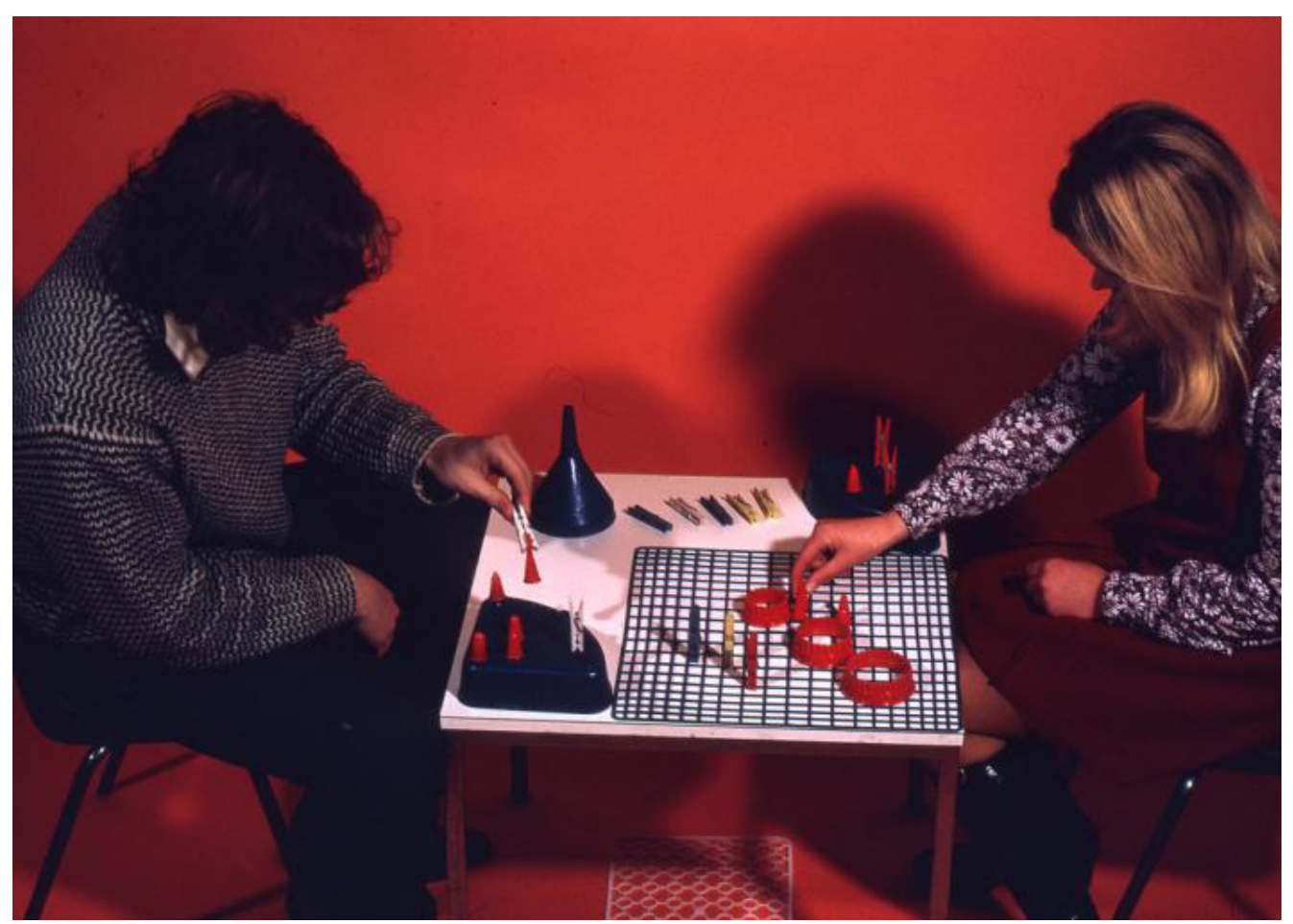

ASCOTT, Transaction set, 1971.

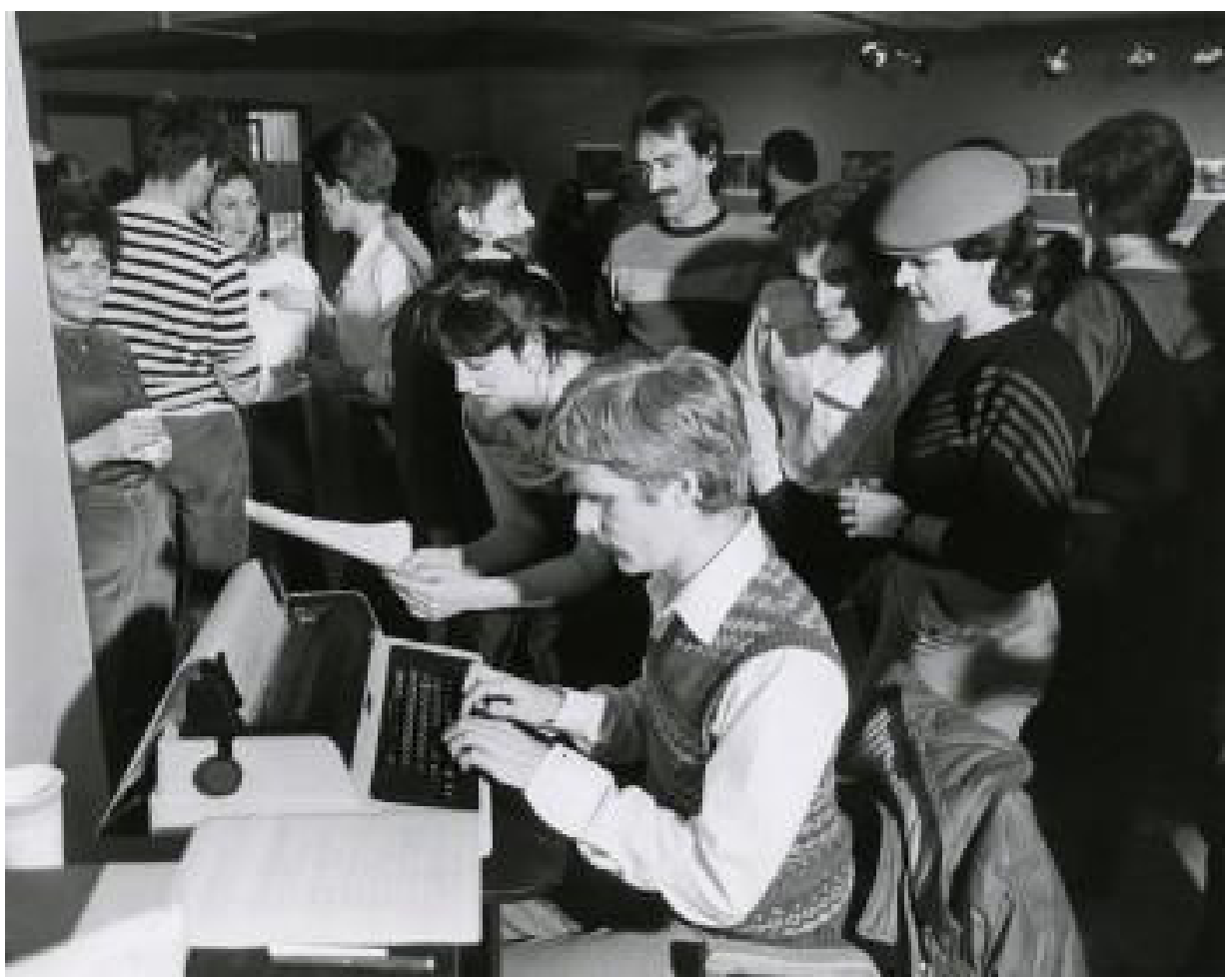

ASCOTT, la plussure du text, a planetary fairt tale, 1983. 


\section{Estudo de caso 2: Jeffrey Shaw}

O australiano Jeffrey Shaw, nascido em 1944 em Melbourne, estudou arquitetura e história da arte e, em Milão e Londres, escultura. A partir de 1966 inicia um trabalho colaborativo, com o Artist Placement Group, de Londres, e o Eventstruture Research Group em Amsterdam.

Em 1969, Jeffrey Shaw tomava seus princípios de ação na arquitetura e no ambiente. A arte teria função revolucionária em um processo de transformação, na qual a arquitetura construiria uma estrutura de morfologia receptiva e indeterminada, capaz de possibilitar a ação, participação e invenção.

Propõe criar eventos e espetáculos não alienados, que alcancem a escala individual do espectador, seus desejos e liberdade, e nos quais a tecnologia traria os recursos abertos ao extraordinário.

Tecnologia como uma fonte aberta ao extraordinário. O que precisamnos agora são demonstrações da aplicação tecnológica fora dos ditados de um programa institucionalizado. Essa exploração aberta se transforma para todos na evidencia de que se trata de uma extensão de seus desejos individuais e de sua liberdade (SHAW, 1969) (tradução nossa) ${ }^{7}$

Suas estruturas pneumáticas, como as waterwalk (possibilitando que pessoas caminhem sobre a água), instigam que o espectador abandone sua passividade e adquira uma posição ativa, através do gritar, pular, fruir as possibilidades acústicas e físicas da estrutura.

Os pneumáticos parecem ser os mais usuais meios de realizar tal programa. Não como uma fantasia futurística no papel, mas como um evento em atual operação, confrontando o monólito institucional em seu âmago (SHAW, 1969) (tradução nossa). ${ }^{8}$

Por outro lado, esse tipo de estrutura pode conter, sob forma de um domo, a proposta de um corpocinema, para projeções tridimensionais de imagens dinâmicas. Seu grupo de pesquisa parte posteriormente para o uso de eletrônica e óptica em eventos híbridos de artes visuais, cinema, teatro, balé e vídeo, predominantemente buscando a interatividade com o espectador.

\footnotetext{
$\overline{7}$ Technology as an open resource for the extraordinary. [...] What is needed now are more and more demonstrations of technological application outside the dictates of the institutionalized programme. Such an open-ended exploitation of technological resources becomes the evidence for all people that it is there as an extension of their individual wills and freedom (SHAW, 1969).

8 Pneumatics seem at this moment to be one of the most useful means of realizing this programme. But not as a futuristic fantasy on paper, but as an event in operation now, confronting the institutional monolith in its midst (SHAW, 1969).
} 

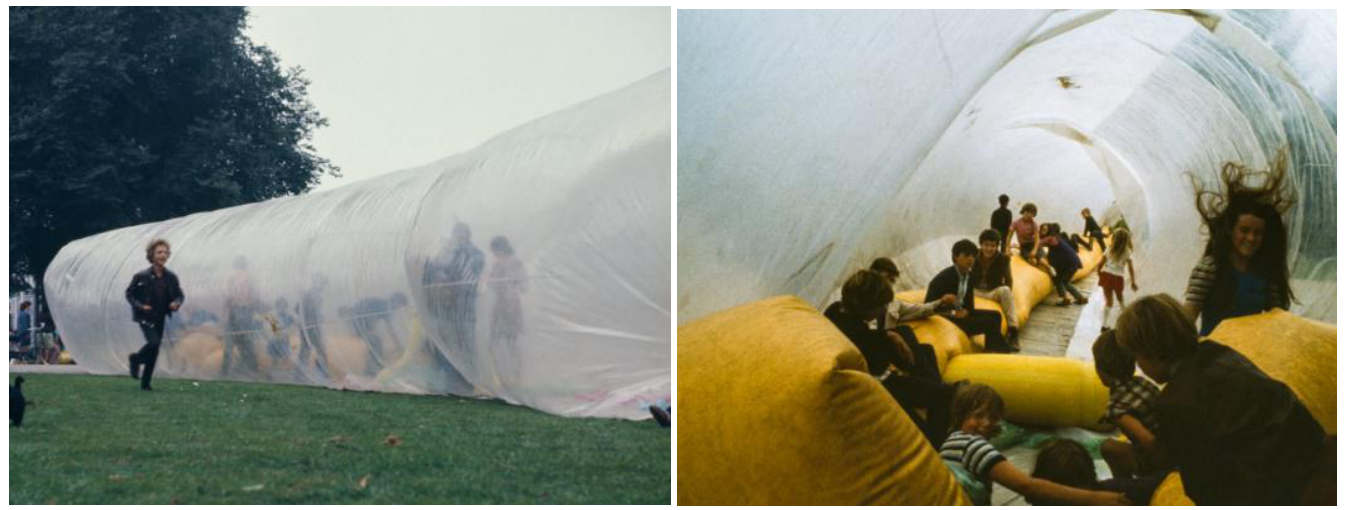

Shaw, Pneumotube, Amsterdam, 1967.
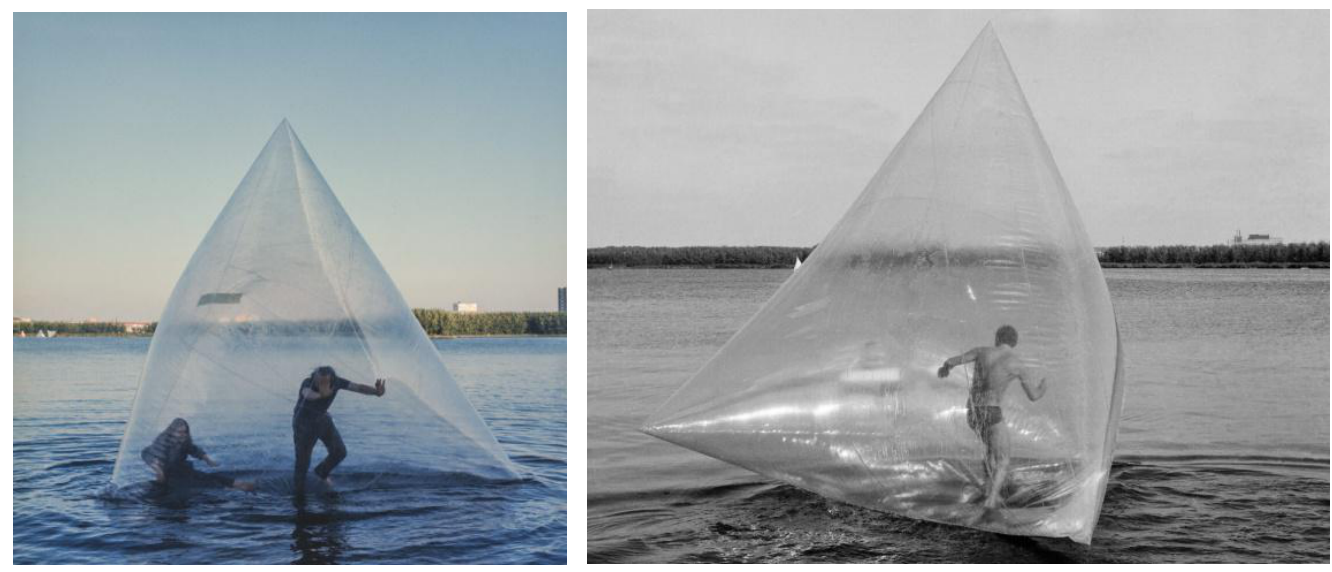

Shaw, Waterwalk, Amsterdam, 1969.

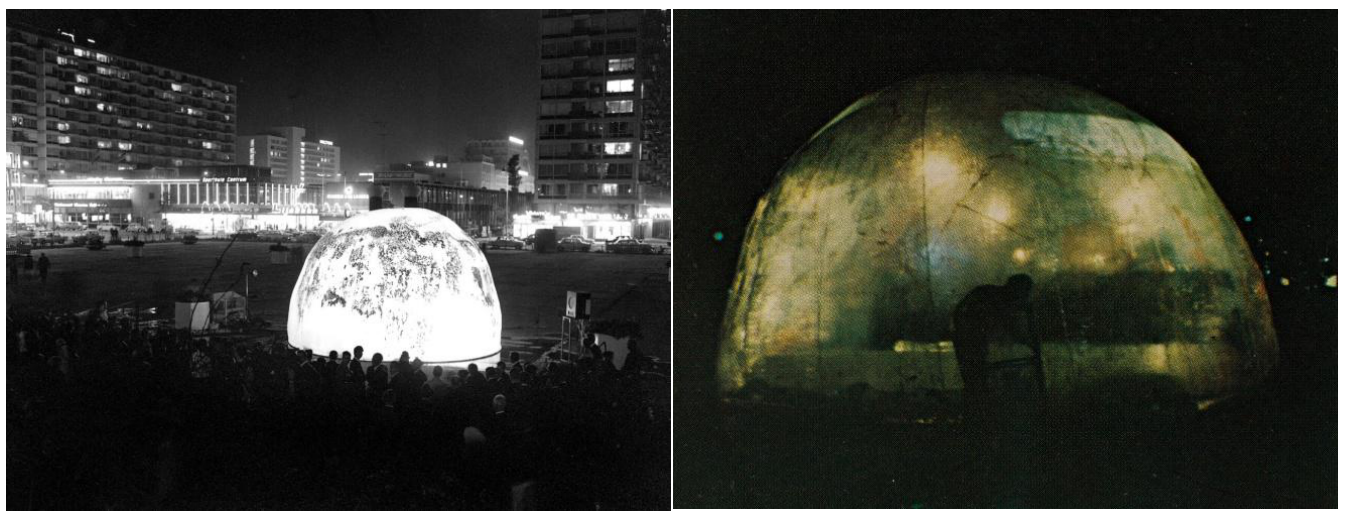

Shaw, Corpocinema, Amsterdam, 1967. 


\section{Consideraçõs finais: tecnologia, participação e a noção de futuro}

Como foi visto, as experiências com movimento, seja real (cinética) ou virtual (óptica), tinham em seus pressupostos tanto uma aproximação a uma constante atualização em relação ao uso de novos materiais, como novas tecnologias, remetendo a uma ideia de transcender aos códigos conhecidos e buscar novas possibilidades.

A percepção colocou-se como um campo privilegiado, e por isso houve uma dedicação à participação efetiva do espectador, seja pela visão ou por outros sentidos.

Os dois princípios articulam a ideia de futuro, seja na proposta da obra futurável de Ascott ou indeterminada de Shaw. Ou seja, a abertura de um vir-a-ser até certo ponto imprevisível, que apenas o espectador pode conhecer através de sua experiência.

Processos, programas ou dispositivos, é a estrutura tecnológica que suporta esse conceito, pois ela própria é signo de um imaginário futuro, maravilhoso, desconhecido. Ascott menciona até a telepatia e a astrologia; Shaw fala de extensão da liberdade. O fator comportamental está inexoravelmente presente, a partir do impulso inicial construído pelo artista.

Experiência lúdica ou sociológica, como aborda Popper, o ser criativo está na origem de tais propostas, e aí seu fator utópico e transformador da sociedade.

\section{Referências}

ASCOTT, Roy. Behaviorables and futuribles. Control, London, n. 5, 1970. Republicado em: STILES, K.; SELZ, P. (ed.). Theories and documents of contemporary art. University of California Press, 1996.

ASCOTT, Roy. Behaviorist art and the cybernetic vision. In: PACKER, Randall; JORDAN, Ken (ed.). Multimedia: from Wagner to virtual reality. New York/London: WW Norton \&Company, 2002, p. 104-120.

ASCOTT, Roy. The cybernetic stance: my process and purpose. Leonardo, v.1, 1968, p. 105-112.

BORGZINNER, Jon. Op Art: Pictures that Attack the Eye. Time, 23 Oct.1964, p. 78-83.

GLASER, Bruce. The changing role of the Modern Museum: a discussion with Lawrence Alloway and William Seitz. Arts Yearbook, n. 9, 1967.

GSCHWEND, Ralfonso. The Development of Public Art and its Future Passive, Active and Interactive Past, Present and Future. Arts. v.4, n.3, p. 93-100.

HESS, Thomas. You can hang it on the wall. ARTnews, Apr. 1965. 
JUDD, Donald. In the galleries: Julian Stanczak at Martha Jackson Gallery. Arts Magazine, Oct. 1964, p. 69.

LEE, Pamela. Chronophobia, on time in the art of the 1960s. Cambridge: The MIT Pres, 2004.

NECHVATAL, Joseph. Origins of Virtualism: An Interview with Frank Popper. CAA Art Journal, Spring 2004, p. 62-77. Disponível em: http://www.eyewithwings.net/nechvatal/popper/intervewww1.html.

PEDROSA, Mário. A Bienal de cá para lá. In: GULLAR, Ferreira. Arte brasileira hoje. Rio de Janeiro: Paz e Terra, 1973.

POPPER, Frank. Art, action et participation: l'artiste et la creativité aujoud'hui. Paris: Gallimard, Editions Klinksieck, 1980.

REYNOLDS, Ann. Robert Smithson: learning from new jersey and elsewhere. Cambridge: The MIT Press, 2003.

RICKEY, George. Kinetic sculpture. In: Art \& artist. Berkeley and Los Angeles: University of California Press, 1956, p. 149-178.

ROSE, Barbara. Beyond vertigo: optical art at the Modern. Artforum International, Apr. 1965, p. 30-33.

SHAW, Jeffrey. Concepts for an operational art. Art and artists, n. 10, jan. 1969, p. 47-49. Jeffrey Shaw

Compendium. Disponível em: http://www.jeffreyshawcompendium.com/concepts-for-an-operational-art/.

TILLIM, Sidney. Optical art: pending or ending? Arts Magazine, Jan. 1965, p. 16-23.

VASARELY, Victor. Notes pour um manifeste (manifeste jaune). Paris: 1955.

Recebido em 06/11/2018 - Aprovado em 15/11/2018

Como citar:

ANDRADE, M. P.. Frank Popper, Roy Ascott e Jeffrey Shaw: visões de um futuro tecnológico e participante nas décadas de 1960 e 1970. ouvirOUver; Uberlândia, v.14,n.2, p.310-321, jul./dez. 2018. Disponível em: http://www.seer.ufu.br/index.php/ouvirouver; DOI:http://doi.org/10.14393/OUV23-v14n2a2018-4 